\title{
Ultrasonographic evaluation of femoral cartilage thickness in patients with familial Mediterranean fever
}

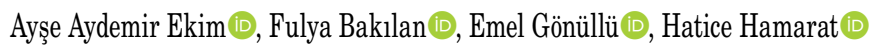 \\ Department of Physical Medicine and Rehabilitation, Eskişehir State Hospital, Eskişehir, Turkey
}

Received: March 13, 2020 Accepted: August 18, 2020 Published online: December 01, 2021

\begin{abstract}
Objectives: This study aims to determine femoral cartilage thickness using ultrasonography in familial Mediterranean fever (FMF).

Patients and methods: A total of 45 patients ( 16 males, 29 females; mean age: $38.5 \pm 9.1$ years; range, 24 to 49 years) with the diagnosis of FMF and 31 healthy individuals (6 males, 25 females; mean age: $37.0 \pm 8.7$ years; range, 25 to 47 years) between January 2016 and July 2016 were included in this study. Clinical data and demographic characteristics of the patients were recorded. All FMF cases in the study were in remission with colchicine treatment. The thickness of femoral cartilage in both knees were evaluated using ultrasonography. Three measurements (mid-point) were taken from both knees (at the medial/lateral femoral condyles and intercondylar area).

Results: Ultrasonographical measurements revealed that cartilage measurements of FMF patients were significantly thinner at both the medial/lateral femoral condyles and intercondylar area on the right knee and at the medial/lateral femoral condyles on the left knee $(p<0.001)$. The cartilage measurements in FMF patients were significantly thinner at the intercondylar area on left knee, compared to those in controls $(\mathrm{p}=0.023)$.

Conclusion: Our study showed decreased femoral cartilage thickness in FMF patients. These findings indicate that even if these patients do not have an attack, they may have subacute and chronic arthritis in their joints, and their femoral cartilage thickness can be affected.
\end{abstract}

Keywords: Familial Mediterranean fever, femoral cartilage thickness, ultrasonography.

Familial Mediterranean fever (FMF) is an autosomal hereditary inflammatory disorder characterized by recurrent attacks of fever and polyserositis. $^{[1,2]}$ Arthritis in FMF typically presents with acute attacks, and the severity of attacks regresses completely within approximately about two weeks. ${ }^{[3]}$ In general, it occurs in the knees, ankles, wrists, sacroiliac, and shoulder. ${ }^{[4]}$ However, chronic/subacute arthritis can be observed in 5\% of patients with FMF. ${ }^{[5]}$ Contrary to acute arthritis, the hips and knees which are weight bearing joints are usually involved in the chronic destructive form. ${ }^{[6]}$ However, the femoral cartilage thickness by using ultrasound (US) of FMF patients has not previously been investigated.

Considering all the above, in the present study, we aimed to evaluate whether the femoral cartilage thicknesses of FMF patients differed from healthy controls and the associations between the measurements and the characteristics of disease or radiological damage scores. In this respect, chronic destructive changes in knee joint of FMF patients were evaluated with musculoskeletal US, which is shown to be a reliable method for femoral cartilage measurement. ${ }^{[7-10]}$

Corresponding author: Ayşe Aydemir Ekim, MD. Eskişehir Şehir Hastanesi, Fizik Tedavi ve Rehabilitasyon Kliniği, 26080 Odunpazarı, Eskişehir, Türkiye. 


\section{PATIENTS AND METHODS}

This cross sectional study was conducted at Eskişehir State Hospital, Departments of Physical and Rehabilitation Medicine and Rheumatology between January 2016 and July 2016. A total of 45 patients (16 males, 29 females; mean age: $38.5 \pm 9.1$ years; range, 24 to 49 years) with the diagnosis of FMF and 31 healthy individuals (6 males, 25 females; mean age: $37.0 \pm 8.7$ years; range, 25 to 47 years) without any chronic disease and knee pain were included in the study. Patients with other inflammatory articular diseases, collagen tissue disorders, malignancy, previous knee surgery, chronic liver/kidney, thyroid diseases and pregnancy were excluded from the study. The Tel-Hashomer criteria were used for the diagnosis of FMF. ${ }^{[1]}$ All patients with FMF were in remission with colchicine treatment. Prior to study, all participants were informed about the nature of the study and a written informed consent was obtained. The study protocol was approved by the Eskişehir Osmangazi University Faculty of Medicine Ethics Committee (13/12/16-80558721/G-322). The study was conducted in accordance with the principles of the Declaration of Helsinki.

Demographic and clinical data of the participants were recorded including age, sex, weight, height, disease duration (the time from the first onset of FMF symptoms), and all medications used.

All measurements were performed by a single physician using a 5 to $10 \mathrm{MHz}$ linear probe (Shimadzu, Diagnostic Ultrasound System, Kyoto, Japan) and this physician who performed the knee US was blind to the group allocation. Both knees of all participants were evaluated for distal femoral cartilage thickness. Distal femoral cartilage assessment was performed, while the patients were lying in the supine position with their knees in maximum flexion. The transducer was placed axially above the patellar outer edge. ${ }^{[12]}$ Cartilage thickness measurements were taken from the mid-points of the medial femoral condyle (MFC) and lateral femoral condyle (LFC), and intercondylar area (ICA). As the distance between the thin hyperechoic line at the synovial space-cartilage interface and the sharp hyperechoic line at the cartilage-bone interface, the cartilage thickness was measured (Figure 1). ${ }^{[13]}$

\section{Statistical analysis}

Statistical analysis was performed using the IBM SPSS for Windows version 21.0 software (IBM Corp.,

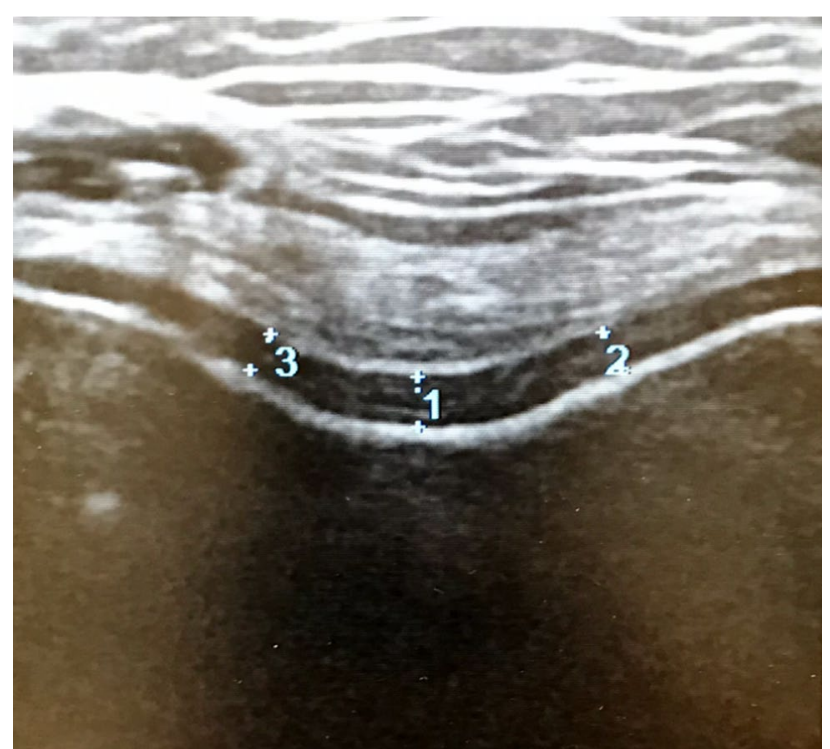

Figure 1. Ultrasonographic image demonstrating the femoral cartilage measurements.

1: IC: Intercondylar area; 2: LC: Lateral condyle; 3: MC: Medial condyle.

Armonk, NY, USA). Descriptive data were expressed in mean \pm standard deviation (SD), median (25-75\%) or number and frequency, where applicable. The distribution of each continuous variable was tested using the Shapiro-Wilk test. Normally distributed variables were analyzed using the independent samples t-test, while non-normally distributed variables were analyzed using the Mann-Whitney $\mathrm{U}$ test. The categorical variables were compared between the groups using the Pearson chi-square tests. A $p$ value of $<0.05$ was considered statistically significant.

\section{RESULTS}

In this study, a total of 90 knees of 45 FMF patients and 62 knees of 31 healthy controls were evaluated. In FMF patients, the median of disease duration was 7 (range, 4-13) years. Baseline demographic characteristics of the patients are presented in Table 1.

For the right knee cartilage thickness measurements at MFC, ICA, LFC, the left knee cartilage thickness measurements at MFC and LFC were found to be thinner in the patients with FMF, compared to the controls $(\mathrm{p}<0.001)$. There were no significant differences in terms of cartilage thickness for ICA in left knee in FMF patients, compared to the healthy individuals $(\mathrm{p}=0.023)$ (Table 2$)$. 


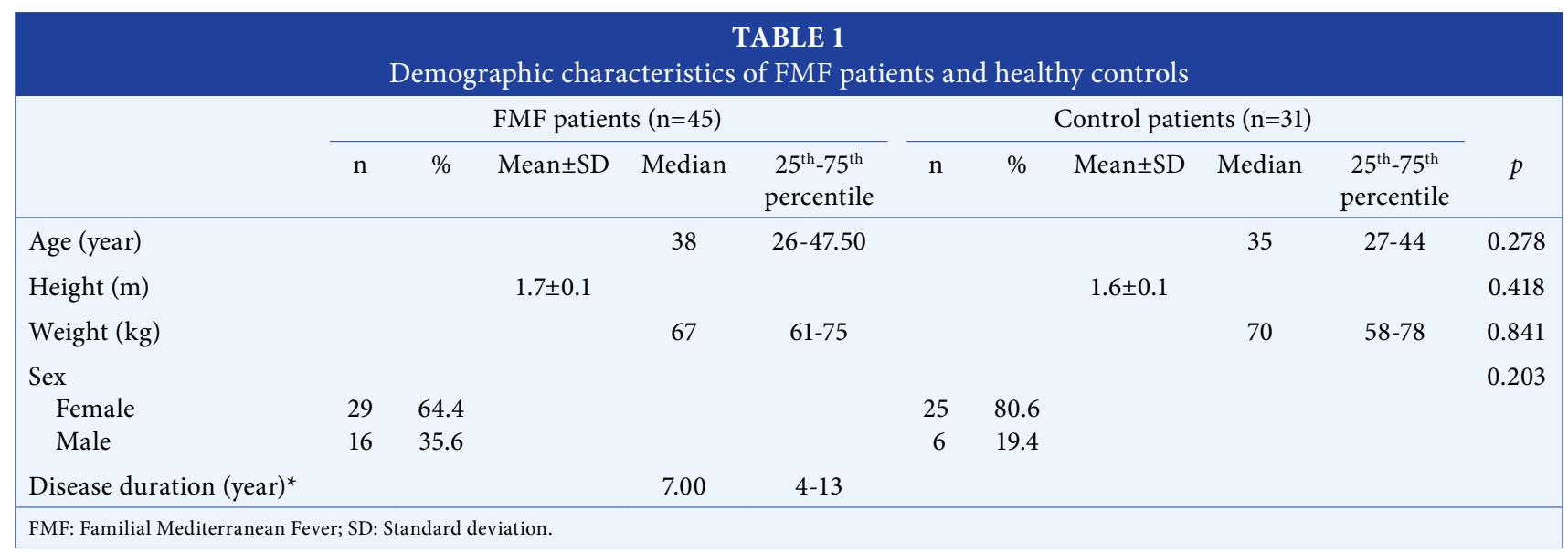

\begin{tabular}{|c|c|c|c|c|c|}
\hline \multicolumn{6}{|c|}{$\begin{array}{r}\text { TABLE } 2 \\
\text { Ultrasonographic evaluation of knee of pa }\end{array}$} \\
\hline & \multicolumn{2}{|c|}{ FMF patients $(\mathrm{n}=45)$} & \multicolumn{2}{|c|}{ Control patients $(\mathrm{n}=31)$} & \multirow[b]{2}{*}{$p$} \\
\hline & Median & $25^{\text {th }}-75^{\text {th }}$ percentile & Median & $25^{\text {th }}-75^{\text {th }}$ percentile & \\
\hline Right MFC & 1.77 & $1.49-1.89$ & 2.15 & $1.88-2.31$ & $<0.001$ \\
\hline Right ICA & 1.98 & $1.77-2.18$ & 2.29 & $2.09-2.50$ & $<0.001$ \\
\hline Right LFC & 1.72 & $1.58-1.88$ & 1.98 & $1.87-2.19$ & $<0.001$ \\
\hline Left MFC & 1.67 & $1.46-1.98$ & 1.98 & $1.78-2.19$ & $<0.001$ \\
\hline Left ICA & 2.08 & $1.78-2.40$ & 2.29 & $2.14-2.42$ & 0.023 \\
\hline Left LFC & 1.87 & $1.68-2.05$ & 2.12 & $1.98-2.31$ & $<0.001$ \\
\hline
\end{tabular}

\section{DISCUSSION}

In the present study, the femoral cartilage thickness of FMF patients was evaluated for the first time in the literature and FMF patients were found to have a thinner femoral cartilage thickness compared to healthy controls.

Arthritis of FMF in the joints usually leaves no sequelae. Particularly in the hip joint, it may be rarely destructive and chronic ${ }^{[14]}$ and chronic arthritis occurs less than $10 \%$ of FMF patients. ${ }^{[15,16]}$ Some of the studies in the literature revealed that chronic arthritis has an effect particularly on the hip and knee joint of FMF patients. ${ }^{[17,18]}$ However, the histological studies have shown chronic fibrosing synovitis, occasionally with bone erosions. ${ }^{[5,17]}$

In the literature, for pediatric patients with FMF, both the presence and distribution of arthritis was screened with bone scintigraphy. Although no patients were experiencing an attack, $51.2 \%$ of FMF patients were found to have joint involvement, as evidenced by the scintigraphic evaluation, and this case proves that subacute and chronic arthritis can still continue, even if patients have no attack. In our study, despite not having an active arthritis, patients with FMF were significantly found to have a thinner femoral cartilage thickness than the control group, and it may be due to possible subacute and chronic arthritis. $^{[19]}$

In their study, Heller et al. ${ }^{[17]}$ reported that an early age was a significant factor for articular disease in FMF which usually affected only single large joint. As such, patients with FMF may become prone to osteoarthritis due to early knee joint degeneration. ${ }^{[20]}$ Similarly, although we studied with an early age group, femoral cartilage thickness was found to become thinner. Moreover, the data have demonstrated that proinflammatory cytokines (interleukin [IL]-10, IL-12, IL-17, IL-18) contribute to the inflammation in attackfree FMF patients, indicating a connection between 
chemokines and subclinical inflammatory cascade. A continuous inflammation is also observed in the pathogenesis, and cytokine levels (tumor necrosis factor-alpha, IL-1-6) have been shown to increase not only during the attacks, but also between the attacks. ${ }^{[21]}$ These findings prove that the inflammatory period continues even in the attack-free period.

Osteoarthritis is the most common condition, particularly among the aged population and it is one of the major causes of disability. This most common chronic condition of the joints leads to hyaline articular cartilage loss and bone changes such as osteophytes. ${ }^{[22-24]}$ In addition, although positioning of the knee can lead to variations, cartilage thickness is evaluated by measuring the width of joint space indirectly. ${ }^{[25]}$ Also, another major limitation is that the thickness of individual cartilage layer cannot be measured, only the sum of the two opposing cartilage layers can be measured. ${ }^{[26,27]}$ Activation of inflammatory processes also occurs in synoviocytes and chondrocytes in osteoarthritis, although it is commonly less severe than FMF. ${ }^{[28]}$ Colchicine modulates the innate immunity and leads to the decrease of different inflammatory processes. Moreover, it has been reported that it has antifibrotic properties. ${ }^{[29]}$ Colchicine has been shown to be a safe and effective treatment in both primary knee osteoarthritis and osteoarthritis with calcium pyrophosphate deposits. Its use is recommended for both functionality and pain. ${ }^{[30]}$ In our study, all patients with FMF were using colchicine, despite the positive effects of colchicine on osteoarthritis, the thickness of femoral cartilage of FMF patients was found to have thinner than healthy controls. This result suggests that patients with FMF can have cartilage degeneration in their joints, even if they are young. Therefore, joint examination should be definitely made and recommendations for joint health should be given during routine controls.

Furthermore, we used US in our study to evaluate cartilage of knee joint, as it is inexpensive, non-invasive, and widely available technique. Moreover, patients accept US easily, as it has no radiation and has no contraindications. ${ }^{[31,32]}$

In the current study, all patients with FMF had a positive Mediterranean fever (MEFV) gene mutation. There were also some limitations in our study: the connection between MEFV gene mutation and cartilage thickness was unable to be examined. As there were some studies about this case which usually include the patients with early diagnosis, the findings were thought to be misleading. Secondly, as there was not enough number of patients with FMF in our clinic, the sample size was limited. Therefore, cautious is needed, while evaluating our results. We believe that FMF disease should be searched in further, large-scale, well-designed studies assessing the articular cartilage.

In conclusion, Our study results showed decreased femoral cartilage thickness in US evaluations of FMF patients, compared to healthy individuals. These findings indicate that even if these patients do not have an attack, they may have subacute and chronic arthritis in their joints, and their femoral cartilage thickness can be affected. Since chronic arthritis may develop in early ages in patients with FMF, early diagnosis is of utmost importance not to be late for the treatment.

\section{Declaration of conflicting interests}

The authors declared no conflicts of interest with respect to the authorship and/or publication of this article.

Funding

The authors received no financial support for the research and/or authorship of this article.

\section{REFERENCES}

1. Korkmaz C, Ozdogan H, Kasapçopur O, Yazici H. Acute phase response in familial Mediterranean fever. Ann Rheum Dis 2002;61:79-81.

2. Bagci S, Toy B, Tuzun A, Ates $Y$, Aslan $M$, Inal A, et al. Continuity of cytokine activation in patients with familial Mediterranean fever. Clin Rheumatol 2004;23:333-7.

3. Ureten K, Calgüneri M, Onat AM, Ozçakar L, Ertenli I, Kiraz S. Interferon alfa in protracted arthritis of familial Mediterranean fever: a robust alternative for synovectomy. Ann Rheum Dis 2004;63:1527.

4. Uthman I, Hajj-Ali RA, Arayssi T, Masri AF, Nasr F. Arthritis in familial Mediterranean fever. Rheumatol Int 2001;20:145-8.

5. Garcia-Gonzalez A, Weisman MH. The arthritis of familial Mediterranean fever. Semin Arthritis Rheum 1992;22:139-50.

6. Sneh E, Pras M, Michaeli D, Shanin N, Gafni J. Protracted arthritis in familial Mediterranean fever. Rheumatol Rehabil 1977;16:102-6.

7. Möller I, Bong D, Naredo E, Filippucci E, Carrasco I, Moragues C, et al. Ultrasound in the study and monitoring of osteoarthritis. Osteoarthritis Cartilage 2008;16 Suppl 3:S4-7.

8. Yoon $\mathrm{CH}$, Kim HS, Ju JH, Jee WH, Park SH, Kim HY. Validity of the sonographic longitudinal sagittal image for assessment of the cartilage thickness in the knee osteoarthritis. Clin Rheumatol 2008;27:1507-16. 
9. Castriota-Scanderbeg A, De Micheli V, Scarale MG, Bonetti MG, Cammisa M. Precision of sonographic measurement of articular cartilage: inter- and intraobserver analysis. Skeletal Radiol 1996;25:545-9.

10. Mathiesen O, Konradsen L, Torp-Pedersen S, Jørgensen U. Ultrasonography and articular cartilage defects in the knee: an in vitro evaluation of the accuracy of cartilage thickness and defect size assessment. Knee Surg Sports Traumatol Arthrosc 2004;12:440-3.

11. Livneh A, Langevitz P, Zemer D, Zaks N, Kees S, Lidar T, et al. Criteria for the diagnosis of familial Mediterranean fever. Arthritis Rheum 1997;40:1879-85.

12. Lee CL, Huang MH, Chai CY, Chen CH, Su JY, Tien YC. The validity of in vivo ultrasonographic grading of osteoarthritic femoral condylar cartilage: a comparison with in vitro ultrasonographic and histologic gradings. Osteoarthritis Cartilage 2008;16:352-8.

13. Yoon CH, Kim HS, Ju JH, Jee WH, Park SH, Kim HY. Validity of the sonographic longitudinal sagittal image for assessment of the cartilage thickness in the knee osteoarthritis. Clin Rheumatol 2008;27:1507-16.

14. Kaushansky K, Finerman GA, Schwabe AD. Chronic destructive arthritis in familial Mediterranean fever: the predominance of hip involvement and its management. Clin Orthop Relat Res 1981;155:156-61.

15. Majeed HA, Rawashdeh M. The clinical patterns of arthritis in children with familial Mediterranean fever. QJM 1997;90:37-43.

16. Brik R, Shinawi M, Kasinetz L, Gershoni-Baruch R. The musculoskeletal manifestations of familial Mediterranean fever in children genetically diagnosed with the disease. Arthritis Rheum 2001;44:1416-9.

17. Heller H, Gafni J, Michaeli D, Shahin N, Sohar E, Ehrlich G, et al. The arthritis of familial Mediterranean fever (FMF). Arthritis Rheum 1966;9:1-17.

18. Sohar E, Pras M, Gafni J. Familial Mediterranean fever and its articular manifestations. Clin Rheum Dis 1975;1:195-209.

19. Aydogan F, Tutanc M, Arica V, Arica S, Gunesacar R. The scintigraphic evaluation and genetic correlation of joint involvements in pediatric patients with familial Mediterranean fever. Hum Exp Toxicol 2013;32:337-43.

20. Ozçakar L, Onat AM, Ureten K, Cetin A, Kiraz S, Ertenli I, et al. Sonographic evaluation of the tendons in familial
Mediterranean fever and Behçet's disease. Joint Bone Spine 2006;73:514-7.

21. Celebi Kobak A, Kobak S, Kabasakal Y, Akarca US. Tumor necrosis factor-alpha gene promoter polymorphism in patients with familial Mediterranean fever. Clin Rheumatol 2007;26:908-10.

22. Lawrence RC, Helmick CG, Arnett FC, Deyo RA, Felson DT, Giannini EH, et al. Estimates of the prevalence of arthritis and selected musculoskeletal disorders in the United States. Arthritis Rheum 1998;41:778-99.

23. Uysal FG, Başaran S. Diz Osteoartriti. Türk Fiz Tıp Rehab Derg 2009:55 Özel Say1 1;1-7.

24. Atamaz F, Hepgüler S, Öncü J. Diz osteoartritinde ağrı ve özürlülükle ilişkili faktörler. Türk Fiz Tıp Rehab Derg 2006;52:119-22.

25. Mazzuca SA, Brandt KD, Katz BP. Is conventional radiography suitable for evaluation of a disease-modifying drug in patients with knee osteoarthritis? Osteoarthritis Cartilage 1997;5:217-26.

26. Yao JQ, Seedhom BB. Ultrasonic measurement of the thickness of human articular cartilage in situ. Rheumatology (Oxford) 1999;38:1269-71.

27. Kim K, Lee HY, Lim SJ. Effects of increased standing balance on pain in patients with knee osteoarthritis. J Phys Ther Sci 2016;28:87-9.

28. Altman RD. Clinical features of osteoarthritis. In: Hochberg MC, editor. Rheumatology. 5th ed. Philadelphia: Elsevier; 2011. p. 1723-30.

29. Leung YY, Yao Hui LL, Kraus VB. Colchicine--Update on mechanisms of action and therapeutic uses. Semin Arthritis Rheum 2015;45:341-50.

30. Restrepo-Escobar M, De Jesus Carmona-Franceschi M, Gomez JHD. Colchicine treatment in adult patients with knee osteoarthritis: Systematic review of the literature. Rev Colomb de Reumatol 2017;24:102-11.

31. Richardson ML, Selby B, Montana MA, Mack LA. Ultrasonography of the knee. Radiol Clin North Am 1988;26:63-75.

32. Harman H, Tekeoğlu İ, Sağ MS, Harman S. Diagnostic value of musculoskeletal ultrasound in newly diagnosed rheumatoid arthritis patients. Turk J Phys Med Rehab 2015;61:326-32. 